\title{
SOME CONSIDERATION ON KNOWLEDGE MANAGEMENT IMPLICATION ON ORGANIZATION'S COMPETITIVENESS
}

\author{
DRAGHICI Anca \\ Faculty of Management in Production and Transportation / Department of Management, \\ Politehnica University of Timisoara, Romania, anca.draqhici@upt.ro
}

\author{
CIORTAN Marius Areta \\ Faculty of Management in Production and Transportation / Department of Management, Politehnica University \\ of Timisoara, Romania, ciortan_marius_a@yahoo.com
}

FLOREA Claudia

Faculty of Management in Production and Transportation / Department of Management, Politehnica University of Timisoara, Romania, florae.claudia@gmail.com

\begin{abstract}
The research described in this paper has been focused on two objectives: to debate the knowledge management's active role for organizations competitive advantage and to describe information technology's capabilities in leveraging the knowledge worker's competencies. For the purposes of this article, competitive advantage is perceived as a strength that provides a market advantage relative to a competitor. Often competitive advantage is related to the core competencies of the organisation, which are frequently based on implicit know-how or tacit knowledge. This intangible, unstructured knowledge is difficult to manage; consequently management has ignored it when designing business strategy. However, the increased competitive pressures of the post-industrial global economy and the exponential advances in computing power have increased management's interest in knowledge as a sustainable source of competitive advantage.
\end{abstract}

Key words: knowledge management, knowledge life-cycle, competitiveness

\section{Introduction - Brief overview of the knowledge management concept}

Knowledge management (KM) is a business activity with two primary aspects: treating the knowledge component of business activities as an explicit concern of business reflected in strategy, policy and practice at all levels of the organisation; and making a direct connection between an organisation's intellectual assets - both explicit and tacit - and growth. KM "in practice often encompasses identifying and mapping intellectual assets within the organisation, generating new knowledge for competitive advantage within the organisation, making vast amounts of corporate information accessible, sharing of best practices, and technology that enables all of the above - including group-ware and intranets," [1]. $\mathrm{KM}$ is "the leveraging of collective wisdom to increase responsiveness and innovation," [9]. While others have represented KM as "... the process by which the organisation generates wealth from its intellectual or knowledge-based assets,” [2]. The usefulness of these definitions is that they illuminate four principles which management must be cognisant of when considering how to manage knowledge for competitive advantage. The KM implications common to these definitions are:

- Knowledge is connected. It is collective wisdom that exists in experiences and perspectives, it's usefulness is derived from its contextual relationships and attributes surrounding its content;

- Knowledge is applicable in new environments. Information applied to address a novel situation for which no precedent exists results in new knowledge, competitive action and growth;

- $\mathrm{KM}$ is a catalyst. It is an action. Knowledge is always relevant to environmental conditions and stimulates action in response to these conditions; and

- KM solutions are dependent on a knowledge sharing culture, [9].

$\mathrm{KM}$ as a concept is going through a maturing process that makes it difficult to define precisely. This lack of an encompassing, succinct definition is not important provided we understand the principles underlying the concept. Important is the recent insight that firms can gain tremendous advantage by applying a more structured and consciously planned KM initiative. KM emerged several years ago just when managers and organisations had finally become comfortable with information management (IM). At 
the time managers perceived that this new concept was nothing more than terminology inflation, dignifying IM with the term knowledge, [5]. The sceptics are correct, as there is a large amount of IM in $\mathrm{KM}$ and KM moves beyond IM in several ways.

\section{Relevant aspects of knowledge management application}

In order to understand what is managed in $\mathrm{KM}$, it is useful to discuss the relationship between data, information and knowledge. However, when management attempts to categorise and index data, information and knowledge in a formal content classification system, issues of interpretation often arise. Data, untabulated facts such as sales figures, are the signals about the organisation and human activity and has little value in itself. Data is easy to manipulate and store in repositories. Information is what data becomes when humans interpret it and contextualize it. It is also the carrier we use to express and communicate knowledge in business. Information has more value than data and is more ambiguous. This is evident from the litany of predictions economists produce from the same economic information. Knowledge is information within people's minds and is valuable as new ideas, insights and interpretations can be applied to information in an effort to generate competitive power and value. In practice, it is difficult to determine when data becomes information and when information becomes knowledge. For practical purposes managers can consider data, information and knowledge, points along a continuum of increasing value and human contribution [6]. Specialists advocate that managers spend little energy on this debate and a lot of energy on adding value to what they have by advancing it along the continuum [15].

The rationale for the link between IM and $\mathrm{KM}$ is derived from the fact that employees in organisations are constantly transforming knowledge into various forms of information such as memos, emails, manuals and reports while they acquire information from others to improve their knowledge. This perpetual regeneration of knowledge into information and information into knowledge is necessary, as people are not always able to share knowledge in person with others due to constraints such as time, the number of people to be informed and geographical location differences. Therefore, KM improves IM by developing easily accessible repositories of information about knowledge. This information guides the employee to the required source of knowledge, whether a document or an expert. Such corporate knowledge maps or expertise directories “... describe a set of knowledge categories, the location of the knowledge and, in some cases, its condition and value" [5]. Many researchers and scientists espouse that the most important knowledge is in people's heads and that the human mind is the primary repository of knowledge; consequently, facilitating access to it through improved IM via knowledge cartography and employee profiling is an important part of KM.

Most approaches to KM benefit from the use of information technology (IT) and improved IM practices. However, there are two other aspects of KM that differentiate it from IM and evidences that $\mathrm{KM}$ is not completely dependent on IT. These truly distinctive aspects of KM can be classified as the creation of innovative knowledge and the application or use of knowledge to beget added value. Unfortunately, these are KM's most difficult features and they are the ones that separate successful KM initiatives from not so successful KM initiatives. Knowledge creation is not a new subject. The works of the philosopher Michael Polanyi (1891-1976) were among the seminal treatises on knowledge creation and its use. He was the first to identify the difference between tacit and explicit knowledge and he was adamant about the intrinsic value of tacit knowledge. In [11] there has been introduced the "Knowledge Life-Cycle", a theory on how organisations create knowledge. They believe that if management recognises and nurtures this process than incremental or radical innovation resulting in business growth is possible. However, as they point out there are strong cultural messages for organisations wishing to adopt the "Knowledge Life-Cycle" process as it is focused on externalising tacit knowledge, making it explicit and then internalising it, making it tacit again throughout the organisation [11]. All KM thinkers agree that this abstract process is one of the most challenging aspects of $\mathrm{KM}$.

The other challenging aspect of KM that differentiates it from IM relates to the way employees apply knowledge and use knowledge in contrast to information. Knowledge, like information, is of no value to business unless applied to decisions that result in competitive action. Plugging information into a previously encountered situation is not the application of knowledge for competitive advantage, as this is easily imitated. This implies that populating electronic and paper-based corporate repositories with information on knowledge is not knowledge management but the intermediate storage of information enroute between employees' heads [9]. KM is not created unless attention is paid to how employees apply and use their knowledge for generating new ideas for future business [5]. 
Comprehending this difference is essential for understanding $\mathrm{KM}$ as "information management consists of pre-planned responses to anticipated stimuli while KM embodies unplanned responses to surprise stimuli” [9]. The significance of this stimulus/response aspect is that knowledge must be internalised to be functional as opposed to information. It must co-exist with human aptitude in order to make intelligent decisions.

Successful knowledge internalisation should result in actions that reflect a change in human behaviour. The way knowledge is applied and stored in the human mind is a critical difference between $\mathrm{KM}$ and IM, one which managers must fully appreciate in order to implement an effective KM initiative. If an organisation's KM initiative is limited to better IM or application of the latest IT without consideration for how knowledge is applied, growth may be limited as the exploitation of collective knowledge to innovate and grow the business is unlikely [4, 5]. Knowledge creation, application and its use are complex issues determined by corporate culture, reward schemes, structure, strategy, skills, staff, management style, values and the design of processes for knowledge work.

The continuous conversion of knowledge into information and information into knowledge is a key element of what companies must do to develop and apply knowledge successfully. There is no doubt that KM incorporates IM and the use of IT to acquire and map information on knowledge and connect employees to knowledge. However, "if knowledge resides primarily in people and it is people who decide to create, use and share their ideas to attain business results, then $\mathrm{KM}$ is as much about managing people as it is about managing information and IT" [5].

\section{Knowledge management's implication on organizations competitiveness}

For the purposes approach, competitive advantage is perceived as an organizational strength that provides a market advantage relative to a competitor. Often competitive advantage is related to the core competencies of the organisation, which are frequently based on implicit know-how or tacit knowledge. This intangible, unstructured knowledge is difficult to manage; consequently management has ignored it when designing business strategy. However, the increased competitive pressures of the post-industrial global economy and the exponential advances in computing power have increased management's interest in knowledge as a sustainable source of competitive advantage. This raises many difficult strategy questions for management, as knowledge is a complex, dynamic, human phenomenon that can be stifled by industrial era management principles or inappropriate information technology. KM influences competitive advantage by robustly linking the core competencies in their respective value chains and connecting the organisation to the client. This linking function is a common, re-occurring theme in the data (Figure 1).

Organisations have implemented KM within the context of corporate and marketing strategy. For these, the generic corporate strategy of choice is to protect and build the market based on brand differentiation with a price premium. The value proposition is developed from the robust linking of core business activities, made possible by the KM process of knowledge mapping. This provides organisational flexibility and co-ordination of resources, as the client interface consultant can share their in-depth knowledge of the client and industry with the consultant approached for advice, allowing the two consultants to create a client valued solution. From this perspective KM influences competitiveness by allowing the organisation to develop solutions that are based on the unique requirements of the client. Such value propositions are differentiated by quality, service and marketing.

The quality of the client knowledge, the speed of service provided and the ability of the interface consultant to market the organisation's knowledge are dependent on the robustness of the links between the core activities. Thus, knowledge repository content decisions are strategic decisions and should be based on what knowledge is critical to achieve corporate strategy. Furthermore, content should be categorised according to the clients' business/industry views, so consultants can quickly find the relevant knowledge.

A key question for success in any differentiation strategy is the extent to which an organisation understands what the customer values. The answer to this question can be found in the KM process of innovating with the customer, as researched by $[2,6,11]$. They cite companies such as Boeing, Xerox and Matsushita Electric Company, as pioneers in involving customers in innovative activities. These organisations brainstorm with customers using a variety of KM techniques and have produced successes such as the disposable toner cartridge, 777 aircraft and the bread-making machine. These KM linking activities serve to differentiate the organisation, as managers become closer to the market and can better sense and respond to customer needs. This KM process of linking and networking with the client is central to the KM initiatives involved in this research. 
Figure 1: Knowledge management in a competitive advantage - the proposed framework

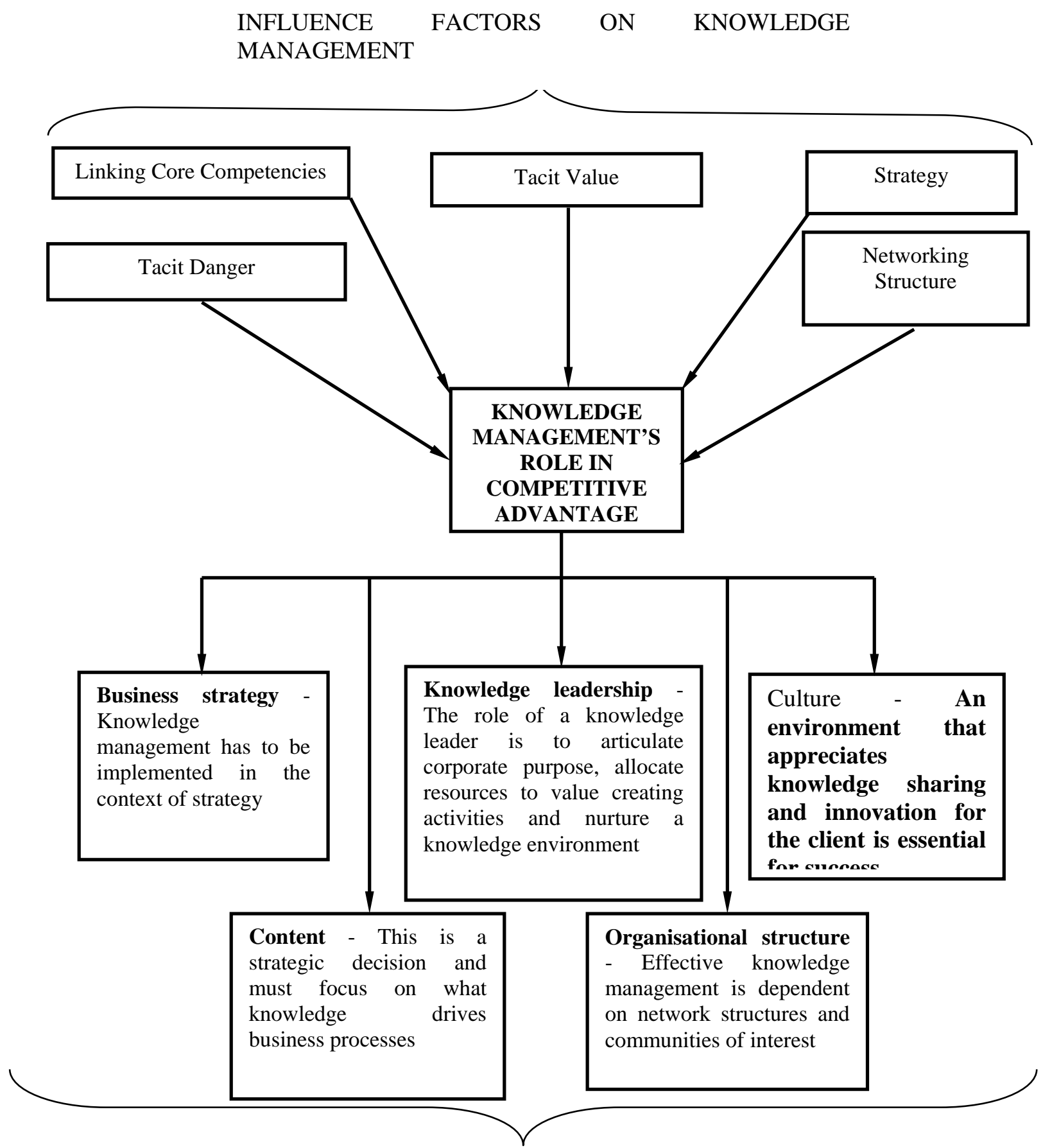

\section{NEW MANAGEMENT PRINCIPLES}

Source: authors own development

In order to differentiate their brands, protect and build the market, organisations must be flexible and responsive to environmental influences. This concerns the important issue of organisational design; that is, where within the structure will strategic and day to day operational decisions be made?

In reality, structure will vary from organisation to organisation and is dependent on a number of variables such as, market conditions, industry structure and stakeholder expectations. KM is instrumental in establishing and preserving a network of professionals, because, whether intentional or not, the network is a product of knowledge mapping activities and the configuration of resources in ad-hoc teams, organised around client knowledge requirements.

These knowledge networks have broad implications for competitive advantage. First of all, the direct networking of professionals to each other's knowledge and experience means, as [7, 14] make clear, that whole layers of management can be cut out of the structure. In non-networked structures, 
management roles serve as relays of information and controllers of resources, at times behaving as barriers to effective business process execution. The removal of these non-value-adding activities should reduce bureaucracy and allow the organisation to respond quickly, in a flexible fashion, to client requests and market influences. For some organisations, the network structure allows their professionals to make real time decisions regarding resources required to be deployed on client issues, without continual approval from the centre. It also allows for and facilitates the ad-hoc formation of teams to deal with these client issues.

Under the network structure, consultants are permitted to organise their time, team composition and intellectual effort in a manner that fits the requirements of the client. Consultants may also be deployed on several projects at a time resulting in an overlap of information and business activities. When the client issue is resolved the team disbands and members move onto new projects, but their map of knowledge in the organisation has improved and they retain contacts for knowledge sources enlarging their network of resources. In order for this resource allocation system to be effective in making knowledge available to others, there must be overlap or redundancy of business knowledge throughout the value chain as no one client interface can capture all relevant knowledge. In [11], there has been debated this type of redundancy in Japanese companies, while [15] has researched it in such American organisations as $3 \mathrm{M}$ and General Electric. Redundancy in this sense is important, as it encourages frequent dialogue and communication across the organisation and the value network. This helps create a common "cognitive ground" among employees and thus facilitates the sharing of tacit knowledge. Redundancy also spreads new explicit knowledge about the organisation and its business environment.

The continuous internalisation of new knowledge by professionals facilitates an environment that is receptive to change. One can infer from this that the network enabled by KMs linking of core business activities is able to change with less complication than non-networked organisations. This produces competitive advantage as networked learning organisations are structured in a fashion that facilitates their reinventing of themselves in response to environmental changes.

The management's role in a knowledge organisation is one of defining goals, providing guidance, focusing professionals on corporate objectives and allocating resources. To do this, management must evaluate what knowledge is required to further corporate strategy and determine where critical knowledge, valued by the client, is located in the organisation. This is the beginning of putting knowledge into the context of strategy $[3,6,12,15]$. For establishing the organisational focus of disbursed networked professionals is essential who may represent a cross section of disciplines with unique agendas. This requires management to establish goals that clearly state performance expectations for the enterprise and for each member. They must also provide feedback that compares results with performance so every member can exercise self-control. In addition, management must empower employees by removing barriers that prevent effective, efficient and economical execution of their duties. This means facilitating access to the information and knowledge required by professionals to service clients' requirements.

The second implication for competitive advantage is that networking of professionals and their exposure to various client issues results in fast and wide development of experience and professional skill. The executives appreciated the inherent value of this type of development and its positive effect on business growth. Research performed by [14] correlates with this view by indicating that the most successful organisations ensure such growth through constantly heightened (preferably customer-driven) problem complexity and thoroughly planned mentoring. This means that development is related to the sharing of tacit knowledge via mentoring and an individual's creation of their own tacit knowledge from experience. The key to this type of development is the networking and linking of core business activities with each other and the client. Such development allows for a continual improvement in skills and a differentiation of the organisation's knowledge relative to competitors who may not have such experience. One danger exists with the linking and combining of tacit knowledge, as made clear by [10]. This can occur because tacit knowledge becomes associated with our values and views of the world. Tacit knowledge becomes embedded in an organisation's core culture and best practices. Organisational strategic drift can result as paradigms may prevent managers from seeing opportunities and threats posed by the environment.

\section{Conclusions}

Recognising knowledge as a competitive resource that requires new management principles to beget business growth is the reason for the current interest in knowledge management. Japanese organisations have long understood the value of developing knowledge assets and managing intellectual capital. They have applied innovative management techniques to promote tacit knowledge sharing and the 
creation of new competitive knowledge. Western organisations seem reluctant to roll out Japanese-style knowledge management initiatives that centre on non-technology techniques for applying discipline to tacit knowledge transfer and innovation. The analysis reveals that the development and support of knowledge communities promoting knowledge redundancy across organisational boundaries is mandatory to establish a knowledge sharing culture and network structure. As knowledge is rooted in human experience and social context, managing it well means paying attention to people, culture and organisational structure, as well as IT. Consideration of the above issues is essential for identifying, developing and supporting knowledge sharing communities that are receptive to contributing, applying and replacing knowledge.

\section{Acknowledgement}

This article has presented the research results obtained through our implication in the national project: Researches based on Knowledge Management Approach Concerning Industry-University Collaboration in the Open Innovation Context (UNIinOI). This work was undertaken through the Partnerships in Priority Domains Programme-PN II, developed with the support of MEN-UEFISCDI, Project no. 337/2014 in Romania. Any findings, results, or conclusions expressed in this article belong to authors and do not necessarily reflect the views of the national authority UEFISCDI.

\section{References}

- Barclay, R.O., Murray, P.C., What is knowledge management?, Knowledge Praxis, Available from http://www.media-access.com/whatis.html, (2000).

- Bukowitz, W., Williams, R., The Knowledge Management Fieldbook, Great Britain, Pearson Education Limited, (1999)

- Carneiro, A., How does knowledge management influence innovation and competitiveness?' Journal of Knowledge Management, 2000 v4 n2, pp.87-98, (2000).

- Davenport, T., Information ecology: Mastering the information and knowledge environment, New York, Oxford University Press, (1997).

- Davenport, T., Marchand, D., Is KM just good information management, Financial Times Mastering Information Management: Complete MBA Companion, in Information Management. Great Britain, Pearson Education Limited, (2000).

- Davenport, T., Prusak, L., Working Knowledge: How Organisations Manage What They Know, United States of America, Harvard Business School Press, (2000).

- Drucker, P. F., The coming of the New Organization, Harvard Business Review: on Knowledge Management, (1988).

- Kotler, P., Marketing Management the Millennium Edition, New Jersey, Prentice Hall Inc., (2000).

- Koulopoulos, T., Frappaolo, C., Smart Things To Know About Knowledge Management, United Kingdom, Capstone Publishing Limited, (1999).

- Leonard, D., Strauss, S., Putting Your Company's Whole Brain to Work, Harvard Business Review: on Knowledge Management, (1997).

- Nonaka, I., Takeuchi, H., The Knowledge Creating Company, New York, Oxford University Press, Inc., (1995).

- Porter, M. E, Millar V. E, How information gives you competitive advantage?, Harvard Business Review: on Knowledge Management, (1985).

- Prusak, L., Making Knowledge Visible, Financial Times Mastering Information Management: Complete MBA Companion In Information Management. Great Britain, Pearson Education Ltd., (2000).

- Quinn, J. B., Anderson, P., Finklestein, S., Managing Professional Intellect: Making the Most of the Best, Harvard Business Review: on Knowledge Management, (1996).

- Stewart, T. A., Intellectual Capital: The New Wealth of Organisations, London, Nicholas Brealey Publishing, (1999) 